\section{Acompañamiento a enfermos de difícil cura a partir de Lc 23,39-43*}

\author{
Manuel Tenjo Cogollo \\ Corporación Universtaria Minuto de Dios, \\ Uniminuto, Colombia \\ http:/ / orcid.org/0000-0001-6703-9063
}

RECIBIDO: 31-08-17. APROBADO: 20-11-17

Resumen: A partir del análisis de Lc 23,39-43 -donde se observan tres maneras de enfrentar el sufrimiento y la muerte- y del dialogo con algunos autores de bioética se presenta la investigación que apunta a la reflexión sobre el sufrimiento y la muerte, encaminada a ayudar a quienes realizan el seguimiento integral a las personas que viven con enfermedades terminales o de difícil cura. Se une el aporte bíblico con el bioético para generar reflexiones de apoyo y crecimiento en medio de situaciones límite, encaminadas a hacer productivo, con un sentido redentor, el sufrimiento y la muerte.

Palabras clave: Sentido del sufrimiento; duelo; muerte; bioética; difícil cura; Lc 23,39-43.
Support for Patients with Difficult-to-cure Diseases Provided from Luke 23:39-43

Авsтract: From the analysis of Luke 23:39-43-where we can observe three ways of dealing with suffering and deathand the dialogue with some authors of bioethics, we present these research that points to the reflection on suffering and death, to help those who carry out a comprehensive monitoring to people who live with difficult-to-cure or terminal diseases. The biblical contribution is combined with the bioethics to generate reflections of support and growth in the midst of extreme situations, aimed to make productive, with a redemptive meaning, the suffering, and the death.

Key Words: Meaning of suffering; Mourning; Death; Bioethics; Difficult cure; Luke 23:39-43.

\section{Cómo CITAR:}

Tenjo Cogollo, Manuel. "Acompañamiento a enfermos de difícil cura a partir de Lc 23,39-43". Theologica Xaveriana 186 (2018): 1-23. https://doi.org/10.11144/ javeriana.tx68-186.aedc

*Artículo de reflexión.

a Autor de correspondencia. Correo electrónico: mtenjo@uniminuto.edu 


\section{Introducción}

El acompañamiento a pacientes terminales o de difícil cura, así como el seguimiento a las familias que afrontan diversos duelos, conduce a reconocer a seres humanos que sufren y a una sociedad de mercado que presenta el sufrimiento y el dolor como si fueran una maldición y no condiciones de la existencia humana. Existen propuestas de tipo mercantilista encaminadas a alejarse del sufrimiento y de la soledad que pueden producir las enfermedades de difícil cura, como señala Sureda ${ }^{1}$. Los laboratorios promueven medicamentos y otros productos que alargan la vida, pero no enseñan a vivir y a morir dignamente. Además, la muerte se ve como un enemigo, como la frustración total y el fracaso de la vida. Se promueve el miedo a la muerte, produciendo alarmas de emergencia que causan pánico, y se buscan soluciones que pueden llegar a ser propuestas irresponsables, o comportamientos antiéticos y moralmente inaceptables, según la investigación de Ospina².

Las propuestas para remediar el sufrimiento y la muerte han sido variadas, con repercusiones teológicas y bioéticas profundas; van desde la trivialización hasta la instrumentalización del ser humano, pasando por una experiencia de un Dios titiritero y sádico que envía el dolor como castigo para la humanidad ${ }^{3}$. Los pacientes sufren trastornos orgánicos, funcionales y degenerativos, sienten desesperanza frente a la inexistencia de una cura a su enfermedad, la amenaza de adquirir una incapacidad residual o las recurrencias frecuentes de la enfermedad. Necesitan entonces encontrar sentido y valor al sufrimiento y a la muerte, para que el final de su vida no se exprese en sentimientos de pérdida y fracaso.

De esta manera, el presente trabajo intenta responder a la pregunta de cómo dar sentido al sufrimiento de los enfermos terminales, a partir de Lc 23,39-43, y exponer una reflexión bioética sobre cómo ayudar a pacientes de difícil cura. Al tener de fondo el análisis semántico de Lc 23,39-43, en la primera parte, y una reflexión bioética, en la segunda, busca aportar al sentido redentor del sufrimiento de personas que padecen enfermedades de difícil cura, al igual que el de sus familias, para brindar algunas recomendaciones a su acompañamiento pastoral.

\footnotetext{
${ }^{1}$ Sureda González, "Aproximación al enfermo terminal y a la muerte", 6.

${ }^{2}$ Ospina, El paciente terminal, la familia, el proceso de duelo y la acción profesional, 9.

${ }^{3}$ Varone, El Dios sádico. ¿Ama Dios el sufrimiento?, 19.
} 


\section{Sentido del sufrimiento y la muerte a partir de Lc 23,39-43}

Se realiza un acercamiento exegético que busque iluminar-fundamentar, desde el Evangelio de Lucas, para develar algunas orientaciones bíblicas sobre las maneras de enfrentar el sufrimiento y la muerte. Por tanto, se utilizan los métodos sincrónicos, especialmente la lectura semántica, porque facilita el acercamiento a las categorías encarnadas en unos personajes que participan del mismo drama y las maneras como se enfrentan el sufrimiento y la muerte en Lc 23,39-43.

\section{Contexto de LC 23,39-43}

El método exige un acercamiento a la identificación del contexto literario, así que antes de llegar al sufrimiento y la muerte de Jesús en la cruz se realiza una mirada a los contextos remoto y próximo que rodean Lc 23,39-43. El final de la existencia de Jesús está llena de diversos sufrimientos que terminan en una muerte dramática, en la que Lucas descarga gran cantidad de elementos propios ${ }^{4}$.

\section{Contexto remoto de sufrimiento y muerte de Jesús}

Lc 23,39-43 se encuentra en la sección llamada "Pasión y muerte de Jesús", que corresponde a los capítulos 22 y 23 del tercer Evangelio. Es una sección cargada del sufrimiento que conduce a la muerte de Jesús; la carga física, emocional y espiritual que recae sobre este hombre es tan brutal, que su respuesta se convierte en un paradigma para enfrentar el sufrimiento continuo y la muerte inminente.

Lc 22-23 está organizado por pequeñas narraciones en torno de Jesús, en las que predominan distintas formas de sufrimiento, hasta llegar a la muerte. La construcción es la siguiente:

- Jesús y sus discipulos: anuncio de la traición, negación y muerte (22,1-46). Es una sección donde Lucas señala el comienzo de la pasión de Jesús con elementos sobresalientes, como la conspiración por parte de los sumos sacerdotes y los escribas contra él, al mismo tiempo que ocurren otros sucesos: la traición del discípulo Judas (vv. 1-6), la celebración de la cena pascual en la que él advierte que va a padecer (vv. 14-18), la institución de la eucaristía, en la que se notifica su derramamiento de sangre (vv. 19-20), y el anuncio de que uno de sus discípulos lo va a traicionar, que genera

${ }^{4} \mathrm{El}$ acercamiento a la obra lucana ha sido ampliamente presentado por numerosos autores y no es motivo del presente artículo. Al respecto, puede verse a Tenjo Cogollo, "La perseverancia en el seguimiento de Jesucristo a partir de algunas comunidades en el Minuto de Dios y confrontación con Lc 8,11-15, 29-35”. 
discusión entre los presentes (vv. 21-23). Después del diálogo con sus discípulos, Jesús divulga el sufrimiento final, que ellos no entienden (vv. 35-38), y termina con la oración en el Monte de los Olivos, donde manifiesta su profundo sufrimiento, mientras que sus discípulos lo abandonan (vv. 39-46).

- Jesús es traicionado, negado, golpeado y acusado en el Sanedrin (23,47-65). Lucas señala que comienzan los sufrimientos de tipo psicológico de Jesús, pues sus discípulos le dan la espalda y las autoridades lo juzgan con testimonios falsos. Las escenas muestran que Jesús es traicionado por Judas y prendido como "un salteador" (vv. 47-53), es negado por Pedro (vv. 54-62), recibe los primeros ultrajes - es golpeado y se burlan de él (vv. 63-65) y es enjuiciado ante el Sanedrín con acusaciones falsas. La defensa de Jesús se vuelve en su contra (vv. 66-71).

- Jesús es conducido ante Pilato y Herodes, declarado inocente pero condenado a la cruz por influencia de las autoridades judias (23,1-25). Jesús tiene que afrontar los ultrajes físicos de manera privada y pública. Es llevado ante Pilato, es acusado con falsedades y se insiste en su culpabilidad. Pilato lo declara inocente por primera vez (v. 4; vv. 1-7) y posteriormente es llevado ante Herodes. Los "sacerdotes y escribas lo acusan con insistencia”, pero él permanece en silencio. Herodes se burla de Jesús y lo devuelve a Pilato (vv. 8-12). Al final, Pilato declara a Jesús inocente por segunda vez (v. 14) y manda darle un escarmiento. Las autoridades judías piden la liberación de Barrabás y la crucifixión de Jesús, pero Pilato declara inocente a Jesús por tercera vez (v. 15); no obstante, lo entrega para que lo crucifiquen (vv. 13-25).

- Jesús es crucificado, muere y es sepultado (23,26-56). El desenlace muestra el mayor sufrimiento de Jesús, tanto psicológico como físico, hasta que llega su muerte y es llevado al sepulcro. Lucas narra que Jesús es conducido hacia el calvario con la cruz a cuestas, que lo acompañan un Simón de Cirene, el pueblo, unas mujeres y dos malhechores que serán ejecutados con él (vv. 26-32), y que es crucificado desnudo en medio de los dos malhechores. Jesús perdona a todos e intercede ante el Padre, "porque no saben lo que hacen” (vv. 33-34). El pueblo lo mira, los magistrados le hacen muecas irónicas, los soldados se burlan y mofan (vv. 35-38), un malhechor lo insulta, el otro busca conciliar y le pide ayuda, ante lo cual recibe la promesa del paraíso (vv. 39-43); finalmente, Jesús da un grito y muere entregando al Padre su espíritu, el escenario se cubre de tinieblas desde el medio día hasta la media tarde (vv. 44-46) y la muerte de Jesús es presentada como "espectáculo": el centurión "ve lo sucedido", la multitud se vuelve "dándose golpes de pecho", los conocidos y las mujeres "ven estas cosas (vv. 47-49). Jesús es sepultado por José de Arimatea y unas mujeres, con afán, por lo que no alcanza a ser embalsamado (envuelto en aromas y mirra) (vv. 50-56).

Es notable que el centro de los ultrajes sea Jesús. Sobre su persona recaen maltratos causados por sus propios discípulos -quienes incurren en la traición, el 
abandono y la negación-, por las autoridades judías representadas en el Sanedrín -con falsos testimonios, ultrajes y remisión a Pilato-, por el mismo procurador romano -quien lo declara inocente tres veces pero lo remite a Herodes, lo manda azotar y lo entrega para que lo crucifiquen-, por el pueblo que se mofa, por los magistrados que se burlan, por los soldados que también se burlan y le dan vinagre, y por uno de los malhechores crucificados a su lado. Además, el cosmos se oscurece de doce del medio día a tres de la tarde. El pueblo, las mujeres y algunos conocidos miran de lejos o de cerca. El segundo malhechor confiesa a Jesús como rey, el centurión romano confiesa a Jesús como justo. La muchedumbre ve todo como un "espectáculo" (theôrían, de donde viene la palabra teatro, théatron, con el sentido del drama griegos); y todo este gran sufrimiento infringido a Jesús termina con su muerte y sepultura apresurada.

\section{Contexto próximo de causas inmediatas del sufrimiento y la muerte de Jesús}

El contexto próximo del drama del sufrimiento y la muerte de Jesús están en 23,33-49, porque obedece al fatal momento de la crucifixión que conduce a la expiración. Se presentan las causas inmediatas del sufrimiento y la muerte de Jesús como un listado de maltratos sucesivos: es crucificado y tratado como malhechor (v. 33); es despojado de sus vestiduras, que se juegan "echando suertes" (v. 34) mientras que el pueblo lo mira; los magistrados le hacen muecas y lo injurian; los soldados se burlan, le ofrecen vinagre y también le injurian, y le ponen el letrero en la cruz (vv. 35-38). Los condenados a muerte hablan entre sí: un malhechor lo insulta (v. 39), el otro dialoga fraternalmente con él (vv. 40-43). Se concluye con señales como el oscurecimiento del cosmos, entre el medio día y la media tarde (v. 44), y la rasgadura en medio del velo del Templo (v. 45), mientras Jesús muere entregando el espíritu al Padre (v. 46). Al final, todos ven lo sucedido como un "espectáculo" (vv. 47-49).

\section{Conclusión}

El sufrimiento y muerte de Jesús es presentado de manera dramática, buscando destruir su recuerdo. Solo se da un momento breve de exaltación de la dignidad del moribundo, cuando uno de los malhechores reconoce el "temor de Dios" y el Reinado de Jesús (vv. 40-42). Después de la muerte de Jesús, como si fuera el peor de los tres malhechores crucificados, aparece otro reconocimiento por parte del centurión romano, quien señala: "Realmente este hombre era un justo" (v. 37). Ante una fuerza

${ }^{5}$ Ortiz, Concordancia manual y diccionario griego-español del Nuevo Testamento, 213. 
destructora, aparecen unas voces de exaltación que buscan recuperar la dignidad, la misión y el sentido de la muerte de Jesús.

Lucas aprovecha una nueva oleada de insultos para presentar el dialogo con los malhechores, la fuerza del perdón y el abandono en las manos del Padre, que aclara el tono negativo de todo el relato. El carácter de victoria no aparece aún con claridad, pero se va mostrando en las últimas palabras de Jesús y en el reconocimiento del centurión romano. Señala Fitzmayer en torno del origen del relato:

El relato de la pasión de Jesús según Lucas es el único que ofrece una escena en la que uno de los dos malhechores crucificados con Jesús se une explícitamente a las burlas e insultos de los espectadores. Pero en seguida es corregido por el otro malhechor, que reconoce la inocencia de Jesús y le pide que se acuerde de él cuando tome posesión de su Reino. Jesús le responde con la promesa de que ese mismo día estará con él en el paraíso (Lc 23,39-43). ${ }^{6}$

Sin duda alguna, la redacción de la escena está inspirada en Mc 15,32: "También le injuriaban los que con él estaban crucificados”. Lucas reconstruye la escena y arma un dialogo entre los tres crucificados.

\section{Actitudes ante el sufrimiento y la muerte en Lc 23,39-43}

Desde los vv. 32-33, Lucas presenta a dos malhechores que acompañan a Jesús y son crucificados, "uno a su derecha y el otro a su izquierda". No describe su procedencia ni la causa de su ejecución, aunque Marshall y Rengstorf $^{8}$ sugieren que pueden ser zelotes, y Fitzmyer anota que pueden ser sicarios?.

Ante el sufrimiento y la muerte se suelen asumir tres actitudes que se ven en los personajes crucificados, en el contenido y el sentido de sus palabras: tienen dolores en su cuerpo, sufren y mueren esa tarde; pero cada uno enfrenta el sufrimiento y la muerte de manera diferente.

\section{Primera actitud: luchar contra el sufrimiento}

En el v. 39, uno de los malhechores habla primero con actitud agresiva (eblasfémei, literalmente: “le lanzaba blasfemias”): “¿No eres tú el Cristo?” Esta expresión no es exclusiva del primer malhechor, sino es parte de la "tercera oleada de insultos al

\footnotetext{
${ }^{6}$ Fitzmyer, El Evangelio según Lucas IV, 499.

${ }^{7}$ Marshall, The Gospel of Luke. A Commentary on the Greek Text.

${ }^{8}$ Rengstof, Nuovo Testamento. Il Vangelo secondo Luca.

${ }^{9}$ Fitzmyer, El Evangelio según Lucas IV, 502.
} 
Crucificado" 10 , y hace referencia directa a "los jefes" del pueblo (v.35), entre el cual se profiere una burla a la realeza de Jesús. Se lee varias veces el ataque contra el Reinado de Jesús (vv. 2.3.11.37.38.39) por parte de las autoridades judías, de Herodes, de los soldados romanos y del malhechor. Enseguida, el primer malhechor añade: "¡Sálvate a ti y a nosotros!” Es la tercera vez que se alude al poder salvífico de Jesús (vv. 35.37.39) con muestras de sarcasmo y egoísmo ("y a nosotros"). Es un ataque directo y violento contra Jesús por parte de alguien que sufre como él, pero que enfrenta su sufrimiento y su muerte adhiriéndose a los comentarios negativos e insultando con ironía y sátira.

Se descubren las siguientes características de una persona que lucha contra el sufrimiento: ataca a quienes se encuentran al lado, busca culpables, irrespeta, responde con la violencia con que es tratado, grita, no mide las consecuencias de sus palabras y acciones, y-como ya está perdido- no le importa si involucra a otros en su desahogo emocional; finge, aparenta, no se siente feliz con nada, aunque quienes se encuentran al lado procuren un mejor ambiente, pierde el carácter y se deja llevar por los comentarios pesimistas y sarcásticos, quiere soluciones egoístas, se une a los agresores para autojustificar su sufrimiento.

\section{Segunda actitud: buscar sentido al sufrimiento}

El dialogo del segundo malhechor tiene dos partes: en primer lugar, la llamada de atención al primer malhechor ${ }^{11}$ y el análisis de su realidad actual (vv. 40-41); y, en segundo lugar, la petición ${ }^{12}$ a Jesús.

Se reflejan las actitudes de la persona que sufre en su cuerpo y espera la muerte con unos elementos distintos al primer malhechor, quien lucha contra el sufrimiento y la muerte. El segundo malhechor refleja las actitudes de buscar sentido al padecimiento presente y a la inmediata muerte. Tales actitudes son las siguientes:

1. En el v. 40, el segundo malhechor dice: “¿Es que no temes a Dios, tú que sufres la misma condena?" El segundo malhechor, a quien "la tradición conoce como Dimas o Dysmas", un nombre que aparece por primera vez en el escrito apócrifo Hechos de

\footnotetext{
${ }^{10}$ Ibíd., IV, 500.

${ }^{11}$ Es un contraste típico de Lucas, en el que dialoga la acción negativa con la positiva: por ejemplo, Juan Bautista y Jesús (7,33-34), María y Marta (10,38-42), el hombre rico y Lázaro (16,19-31), el fariseo y el publicano (19,9-14).

${ }^{12}$ Hay una resonancia de Gn 40 sobre el panadero y el copero, presos con José en Egipto. El copero fue restituido en su cargo, mientras que el panadero acabó colgado de un árbol. José, después de interpretar positivamente el sueño del copero sobre lo que le traería el futuro, añadió: "Acuérdate de mí... cuando te vaya bien y pórtate misericordiosamente conmigo". Si en el relato del Génesis el copero acaba llevándose a José a un puesto encumbrado en la corte, en el relato lucano Jesús se lleva al malhechor al paraíso. Ver a Brown, La muerte del Mesías, II, 1187.
} 
Pilato 10,2 -como presenta Fitzmyer ${ }^{13}$-, manifiesta temor de Dios, que en el Antiguo Testamento es la base de la sabiduría, y en Lucas es el reconocimiento a Dios, quien tiene el poder de enviar al hades después de la muerte (Lc 12,4-5).

Además, el segundo malhechor manifiesta el temor de Dios como base de la justicia divina opuesta a la represión que padece Jesús. El segundo malhechor reprende a su compañero, señalando que los tres han sido judicializados y sentenciados a morir en la cruz, pero que uno es inocente, de manera que el juicio realizado por Pilatos y las autoridades judías es injusto. El justo que sufre y muere por ser tratado injustamente. Quien sufre con Jesús busca una comprensión de la justicia divina basada en el temor de Dios.

2. En el v. 41, el segundo malhechor dice: "Y nosotros con razón, porque nos lo hemos merecido con nuestros hechos; en cambio, este nada malo ha hecho". Son evidentes los dos elementos en la reflexión de su sufrimiento y su inminente muerte:

- El primero, que el malhechor del discurso reconoce que él y su compañero han sido condenados justificadamente, por sus acciones, de manera que merecen la situación que están viviendo. Conduce a recordar la afirmación de que "lo que se siembra se cosecha” (Ga 6,7), pues estos dos son crucificados "con razón” y como consecuencia de sus "hechos". En la situación límite del sufrimiento y la muerte, el segundo malhechor reflexiona sobre su estilo de vida y reconoce que su situación actual es causada por sus decisiones-acciones pasadas.

- El segundo elemento muestra la declaración de inocencia de Jesús, en sintonía con la triple inocencia que hace Pilato (vv. 4.14.22) y que realizará el centurión romano después de la muerte de Jesús (v. 47). Es un notable contraste: las autoridades gubernamentales y militares del Imperio Romano declaran inocente a Jesús, y un malhechor condenado a muerte se pone de su lado, a pesar de que las autoridades judías lo acusan "con insistencia" (v. 10), reclaman su muerte como un malhechor (v. 23) y se burlan de su mesianismo (v. 35).

Todo indica que este segundo malhechor toma una actitud más solidaria y sensible ante las situaciones límite de la existencia humana, al reconocer que la situación actual es consecuencia de su pasado, pero que las buenas acciones de Jesús no tienen por qué llevarlo al tormento que está viviendo. Esta es una reflexión siempre vigente: ¿Por qué le pasa tal sufrimiento al inocente Jesús si ha sido bueno? Parece que ese sufrimiento carece de sentido.

3. En el v. 42 aparece la petición del segundo malhechor: "Y decía: 'Jesús, acuérdate de mí cuando vengas con tu Reino'”. El segundo malhechor se dirige a Jesús

${ }^{13}$ Fitzmyer, El Evangelio según Lucas IV, 503. 
llamándolo por su nombre, "Jesús"14, y esta familiaridad sorprende, ya que en ningún otro lugar de ningún Evangelio nadie se dirige a Jesús simplemente por su nombre, sin especificación alguna o calificación reverencial. La confianza que tiene un reo de muerte al tratar a Jesús por su nombre no es irreverencia, pues va a pedir los beneficios de su soberanía. Brown señala al respecto: Los soldados se han burlado de Jesús como "el rey de los judíos". Como consecuencia de ello, el malhechor entiende que se ha cometido una injusticia con Jesús y concluye que realmente él gobernará un reino. ${ }^{15}$

Fitzmayer señala que "la petición de 'acordarse' puede ser un eco de algunos pasajes veterotestamentarios, como Gn 40,14 o Sal 106,4. Peticiones semejantes se encuentran a veces en inscripciones funerarias judías" ${ }^{16}$. El malhechor pide a Jesús que se acuerde de él, quizás pensando que el destino de Jesús podría ser diferente del suyo propio. Su petición se basa en el título que se atribuye a Jesús en el letrero que preside la cruz. Lo único que pide es un recuerdo benévolo, porque ya no puede hacer nada para merecerlo.

Así, el concepto de la subida de Jesús al cielo, desde la cruz, es una interpretación creíble, porque el segundo malhechor espera que Jesús salga victorioso y obtenga su reino, por lo cual le pide que se acuerde de él en ese momento ${ }^{17}$.

El segundo malhechor interviene con un tono conciliador, reverente y en busca de esperanza ante su muerte inminente. Explica el origen del sufrimiento, consciente de que lo que se siembra se cosecha. Mira a Jesús, quien también padece el mismo sufrimiento. Busca cómo dar sentido a ese sufrimiento porque ya no tiene otra salida digna. Espera que Jesús pueda dar sentido al sufrimiento que padece. Le hace una petición que correspondería conceder a un rey, pero lo trata fraternalmente con su nombre: "Jesús", con lo cual señala que este puede tener misericordia porque padece el mismo sufrimiento y le espera la misma muerte ${ }^{18}$.

${ }^{14}$ En el v. 42, se descubre un problema de crítica textual, pues en algunos códices (como A, C3, W, T, A, 0, 0124, 0135) y en algunas versiones antiguas (como las siríacas y las coptas) se lee: elegen to Iesou, mnesthetimou, kyrie ("decía a Jesús: Señor, acuérdate de mí"). No la sigue el autor del presente artículo porque parece obedecer a un esfuerzo por evitar que el malhechor se dirija a Jesús llamándolo por su nombre propio. Otro problema aparece en el códice $\mathrm{D}$, que dice strapheis pros ton kyrioneipenauto ("volviéndose hacia el Señor, le dijo"). Tampoco la sigue porque suena un tanto peculiar, tratándose de una súplica dirigida a un crucificado, ya que se ve una actitud muy coloquial, como si estuvieran en una sala de la casa y no en un patíbulo.

${ }^{15}$ Brown. La muerte del Mesías II, 1193.

${ }^{16}$ Fitzmyer, El Evangelio según Lucas IV, 504.

${ }^{17}$ Brown, La muerte del Mesias II, 1195.

${ }^{18}$ Fitzmyer, El Evangelio según Lucas IV, 501. 
Cuando las personas buscan un sentido espiritual al sufrimiento y a la muerte tienen una actitud más amable y cordial con las personas que las rodean, saben esperar en Dios y esperan el desenvolvimiento de la vida. Porque la muerte hace parte de la vida.

\section{Tercera actitud: dar sentido al sufrimiento}

En el v. 43 sobresalen algunas palabras: "Yo te aseguro: hoy estarás conmigo en el Paraíso". Existe un contraste entre el silencio de Jesús ante las burlas y su respuesta al segundo malhechor, pues las últimas palabras de su vida están dirigidas a un ser humano que no pide señales, sino que reconoce su situación ante el rey que llegará pronto a su reino.

La expresión "yo te aseguro" -que en otras traducciones dice "en verdad" (en griego, amén) - tiene el sentido de resaltar un aspecto que no admite debate y que se presenta con solemnidad, superando toda expectativa ${ }^{19}$. Se manifiesta la misericordia de Jesús, quien en momentos límites de su existencia sigue dando sanación y esperanza: y ello no ocurre solo con el malhechor: también ha curado la oreja del sirviente del sumo sacerdote $(22,50-51)$ que le era hostil; su presencia ha subsanado la enemistad entre Herodes y Pilato $(23,12)$; espontáneamente ha rogado a su Padre que perdonase a quienes lo han crucificado $(23,34)$... Jesús muestra que su sufrimiento y muerte son productivos y victoriosos en medio de un ambiente de fracaso y burla.

La siguiente expresión "hoy" o "en este día” (en griego: sémeron) tiene el sentido cronológico (ese mismo día) y también un sentido escatológico: el primer día del resto de la eternidad, porque es la salvación del pecado y de la muerte inaugurada por Jesús y entregada al último discípulo que se acerca a él.

En seguida aparece la relación "estarás conmigo", pues "el otro" malhechor ha pedido que Jesús se acuerde de él, y le es concedido mucho más: “...porque el estar con la respuesta de Jesús implica no solo el cumplimiento de la petición, sino también relación estrecha", como señala Brown ${ }^{20}$. Jesús le da un papel de discípulo porque, en 22,28-30, el Maestro dice a los Doce: "Vosotros sois los que habéis permanecido conmigo en mis pruebas", y en recompensa les otorga el privilegio de comer y beber a su mesa en el Reino. Sobre esa analogía, Jesús promete que el malhechor estará con él. Esto muestra que es mucho más que estar en su compañía en el paraíso: supone compartir su triunfo de su Reinado ${ }^{21}$.

\footnotetext{
${ }^{19}$ Brown, La muerte del Mesias II, 1196-1197.

${ }^{20}$ Ibíd., 1197.

${ }^{21}$ Plummer, "Luke", 535, citado por Brown, La muerte del Mesías II, 1197.
} 
La expresión "paraíso", ha generado gran debate entre los exégetas², y el autor de este artículo se queda con las propuestas de Brown y de Fitzmyer, cuando señalan que el paraíso es la felicidad suprema, la esperanza superior, el destino definitivo, el ámbito de $\operatorname{Dios}^{23}$. Como señala Brown:

Lucas está enseñando a sus lectores como recibir con paciencia el sufrimiento y convertirlo en ocasión de ganar el favor de Jesús. La opinión más sostenida es también la más obvia: aquí se muestra cómo la gratuita misericordia de Dios es ejercida por y en Jesús. ${ }^{24}$

Ahora interviene Jesús, con una frase sencilla y esperanzadora para el segundo malhechor y para quienes buscan el sentido del sufrimiento y la muerte en una experiencia de la Theologia Crucis $^{25}$. El sufrimiento adquiere un sentido redentor porque se entiende por redentor un inocente que toma el lugar del condenado. El sufrimiento y la muerte de Jesús en la cruz es redentora.

[Lucas tiene la intención] de presentar el aspecto salvífico de la muerte de Jesús: la condición regia de la que será investido, una vez que haya 'entrado en su gloria' (Lc 24,26) y haya sido "exaltado" (Hch 2,32-36), no dejará de tener un efecto salvífico sobre el sufrimiento de los seres humanos, incluso de los malhechores crucificados. Ahí queda resumida la Theologia Crucis de Lucas. ${ }^{26}$

En consecuencia, el sufrimiento y la muerte de Jesús se convierten en una experiencia dolorosa y salvífica a la vez, que pide la búsqueda honesta del "otro" malhechor, para acogerse a la misericordia de su Maestro y recibir las bendiciones de la redención, con una esperanza viva en la eternidad y en la realeza de Jesús. Esta puede establecer una nueva manera de enfrentar el sufrimiento y la muerte: darle sentido redentor, en el cual el inocente asume su sufrimiento como bendición para otras personas en la dimensión del encuentro y la solidaridad.

\section{Sufrimiento y muerte en enfermos de dificil cura}

$\mathrm{Al}$ tener en cuenta las tres maneras de enfrentar el sufrimiento y la muerte señaladas en Lc 23,39-43, se realizará a continuación el acercamiento a las realidades que sufren los pacientes y familiares de enfermedades de difícil cura.

\footnotetext{
${ }_{22}$ Pueden verse los múltiples debates sobre el tema del "paraíso" en Brown, La muerte del Mesías II, 1198-1200.

${ }^{23}$ Brown, La muerte del Mesías II, 1200; Fitzmyer, El Evangelio según Lucas IV, 505.

${ }^{24}$ Brown, La muerte del Mesías II, 1200.

${ }^{25}$ Fitzmyer, El Evangelio según Lucas IV, 504.

${ }^{26}$ Ibíd. IV, 501-502.
} 
Existen diversas respuestas ante el sufrimiento de un paciente terminal y ante sus diversos tratamientos médicos asistidos por profesionales y por familiares, en la Unidad de Cuidados Intensivos o en el hogar; pero esas respuestas no siempre son movidas por un amor oblativo sino por una productividad familiar y social.

\section{Respuestas alarmantes ante el sufrimiento y la muerte}

El ser humano carece de un bagaje que le ayude a afrontar la realidad de la muerte: como dice Ana María Ospina, "la muerte es el acontecer humano más temido universalmente" ${ }^{27}$. Entonces, cuando un paciente enfrenta el sufrimiento de una enfermedad terminal -y además degenerativa o de difícil cura- tiene inicialmente una reacción de negación, por distintos miedos, como señala Ospina en su orientación para acompañar pacientes terminales ${ }^{28}$. Existe una identificación con el primer malhechor crucificado con Jesús (Lc 23,39 señalado antes), quien lucha contra el sufrimiento, aumentando el dolor y aferrándose a la vida.

Esta realidad conduce a tomar posiciones demasiado radicales, como los tratamientos extremos para salvar la vida física de la persona, por un lado, y la propuesta de la eutanasia por el otro. Se generan problemas éticos ante el sufrimiento y la muerte personal o de familiares muy queridos.

\section{Primera respuesta alarmante: tratamientos probables}

En este caso se somete al paciente a toda clase de probabilidades médicas o de otra clase, para mantenerlo "entre nosotros" -como se dice-, pero movido por secretas esperanzas, y en ocasiones provocando la "deshumanizadora tecnificación en las últimas fases de la enfermedad", como señala Sureda ${ }^{29}$. Esto conduce a enfrentar tratamientos con riesgos éticos como los siguientes:

- Transplante de órganos. Cada día crece la transplantología de pequeños y grandes órganos, mediante la cual -según anota García Marcos- se busca un "interés por el enfermo para evitar el daño y procurar el bien" ${ }^{30}$; pero -como señala el mismo autor- "es posible que los excesos hicieran ver con mayor seriedad las necesidades de subordinar estas nuevas técnicas a criterios éticos" ${ }^{31}$, pues se debe

\footnotetext{
${ }^{27}$ Ospina, El paciente terminal, la familia, el proceso de duelo y la acción profesional, 9.

${ }^{28}$ Ibíd., 18.

${ }^{29}$ Sureda González, "Aproximación al enfermo terminal y a la muerte”, 6.

${ }^{30}$ García Marcos, “Aspectos éticos del transplante de órganos”, 253.

${ }^{31}$ Ibíd., 254.
} 
apreciar los costos económicos por la demanda, la fuente de donde provienen los órganos, las formas de adquisición y las probabilidades de bondad para el paciente.

- Tratamientos experimentales. Son los tratamientos y medicamentos (diferentes al estándar) que siguen un protocolo clínico, pero que no consiguen el reconocimiento médico internacional, y muchos de ellos son de difícil disponibilidad ${ }^{32}$.

- Vida vegetativa. Son los sistemas clínicos que buscan mantener viva a la persona, aunque ella no tenga ningún signo evidente de conciencia y de relación con el medio ambiente. Otros sobreviven sin mayores soportes tecnológicos. Señala Jordi Rivero: "Algunas de las personas con atención apropiada y rehabilitación son capaces de salir del estado vegetativo" ${ }^{33}$. De todas maneras, la persona debe seguir siendo atendida y recibiendo el apoyo en hidratación y alimentos adecuados.

- Escape en espiritualidades mal orientadas. Ante el desespero de los familiares del paciente, se buscan medidas extremas como llegar a espiritualidades mal enfocadas, brujería o espiritismo. Algunos espiritistas como David Morales señalan que la enfermedad es una prueba divina:

El fenómeno especifico de la enfermedad, el espiritismo lo ve como una prueba, como una vía de depuración, y ve también sus causas en daños o maleficios echados por santeros, vuduistas, incluso por personas comunes y corrientes que sin conocer que la fuerza de sus pensamientos afecta a otros. ${ }^{34}$

Así se buscan soluciones "mágicas" e inmediatistas que en ocasiones pueden resultar absurdas e impedir procedimientos clínicos adecuados, porque se afirma radicalmente que la brujería puede curar y se pueden realizar tratamientos espiritistas para sanar enfermedades que las ciencias de la vida desechan.

- Sedación terminal. En algunos casos, y dependiendo del protocolo médico, del consentimiento de la familia o del paciente -si ello es posible-, se utiliza la sedación terminal.

Se entiende por sedación terminal la administración deliberada de fármacos para producir una disminución suficientemente profunda y previsiblemente irreversible de la conciencia en un paciente cuya muerte se prevé próxima, con la

\footnotetext{
32 Sureda González, "Aproximación al enfermo terminal y a la muerte”, 3.

${ }^{33}$ Rivero, “¿Qué significa estar en estado vegetativo?”.

${ }^{34}$ Morales, "La medicina contemporánea y su vínculo con el espiritismo. Notas de la Sociedad Espiritista Cubana".
} 
intención de aliviar un sufrimiento físico y/o psicológico inalcanzable con otras medidas y con el consentimiento explícito, implícito o delegado del paciente. ${ }^{35}$

Sureda González señala que la sedación terminal es éticamente correcta cuando tiene los siguientes propósitos: mitigar el sufrimiento, evitar la provocación intencionada de la muerte, esperar algún tratamiento alternativo que consiga los mismos efectos principales sin el efecto secundario que sería el acortamiento de la vida ${ }^{36}$.

\section{Segunda respuesta alarmante: eutanasia}

La Organización Mundial de la Salud, OMS, define la eutanasia como la "acción del médico que provoca deliberadamente la muerte del paciente" ${ }^{37}$. La eutanasia se puede realizar por acción directa, por ejemplo, proporcionando una inyección letal al enfermo, o por omisión, por ejemplo, no proporcionando el soporte básico para su supervivencia.

En ambos casos, la finalidad es la misma: acabar con una vida enferma. Como señala Sureda González: "La eutanasia no resuelve los problemas del enfermo, sino que destruye a la persona que tiene los problemas"38. De esta manera, ante el sufrimiento y la muerte personal o de un familiar, se busca la respuesta de la eutanasia para salir del "problema" rápidamente. Sin embargo, la discusión médica sobre la ilicitud de la eutanasia es compleja, como anota Herranz ${ }^{39}$.

Los avances científicos actuales pueden ayudar a superar de manera eficaz el dolor y la dignificación del paciente al final de su vida, haciendo que la ciencia avance y supere la "pereza" de la investigación ante enfermedades de difícil cura.

No se busca "matar por compasión", sino contribuir a la dignificación de la persona al final de su vida, con la ayuda del médico y la cooperación de tratamientos clínicos adecuados ${ }^{40}$.

Algunas personas promueven la eutanasia mediante una manipulación de las definiciones y del manejo de un lenguaje ambiguo en el cual el público en general entiende algo distinto de lo que se dice, de acuerdo con León Correa ${ }^{41}$. Por ejemplo, a partir de la definición etimológica, de que la eutanasia es la "buena muerte", la "muerte

\footnotetext{
${ }^{35}$ Porta y Guinovart, Definición y opiniones acerca de la sedación terminal: estudio multicéntrico catalano, 108-115.

${ }^{36}$ Sureda González, "Aproximación al enfermo terminal y a la muerte", 8.

${ }^{37}$ OMS, citado por Sureda González, "Aproximación al enfermo terminal y a la muerte", 6.

${ }^{38}$ Ibíd., 9.

${ }^{39}$ Herranz, "Eutanasia o medicina", 21-22.

${ }^{40}$ León Correa, "El debate actual sobre la legislación de la eutanasia”, 39-52.

${ }^{41}$ Ibíd., 39-52.
} 
asistida" o el "derecho a morir dignamente", señalan la necesidad de condolerse con el paciente y con su familia al ver el fuerte sufrimiento de una enfermedad terminal y degenerativa, o la vida vegetativa, o la vida asistida por maquinas en la Unidad de Cuidados Intensivos.

Sin embargo, en el fondo, se esconde la irresponsabilidad por la defensa de la vida, la atención adecuada al enfermo terminal, la preocupación económica y el descuido de la investigación médica.

El autor del presente texto no está de acuerdo con la promoción de la eutanasia sino con las distintas maneras de promover la calidad de vida que conducirán a ver la muerte como un paso hacia la eternidad, y, por tanto, como una oportunidad singular de hacer grandes donaciones. La muerte es la oportunidad de evaluar la calidad de la vida que se ha tenido.

Es necesario tener en cuenta que "la tolerancia de la eutanasia no cambia a la medicina, ni amplía el campo de la actuación del médico. La eutanasia sustituye la medicina" ${ }^{42}$-como afirma Herranz-, causando decaimiento en los avances médicos, desconfianza entre el paciente y el cuerpo médico, pérdida de autonomía del paciente y de su familia, y falta de protagonismo en la toma de decisiones ante la enfermedad y la muerte.

\section{Respuestas conciliadoras ante el sufrimiento y la muerte}

Otras opciones ante el sufrimiento y la muerte de enfermos de difícil cura que se encuentran al final de su vida, o de familiares cercanos a estos, buscan distintos tipos de conciliación y negociación con la vida, la muerte, o con la idea que tengan de Dios. Esta actitud se puede relacionar con la del segundo malhechor, quien buscó el origen y sentido de su sufrimiento y muerte (Lc 23,40-42), y esperó una respuesta positiva en Jesús.

\section{Algunas respuestas conciliadoras}

En los países latinoamericanos, con marcadas costumbres religiosas, se tejen creencias de tipo piadoso que buscan responder al sufrimiento y la muerte con respuestas un tanto superficiales como las siguientes:

- " Nadie sabe el día ni la hora...”. Está basada en Mt 24,36, pero al sacarla de ese contexto, fomenta algún tipo de resignación.

- "Dios nos visitó y se llevó al que estaba listo". Otra por el estilo es: "Dios vino a buscar al fruto más maduro y encontró a...”. Genera una idea de resistencia

${ }^{42}$ Herranz, Comentarios al Código de Ética y Deontología Médica de la Organización Médica Colegial. 
a Dios, porque si él visita para causar dolor y llevarse a las personas amadas, es mejor que no vuelva.

- $\quad$ "Algún pecado ha de estar pagando y hasta que no se ponga en paz... no se va". Muestra una mentalidad retributiva de un Dios que manda el sufrimiento y la muerte para castigar el pecado personal o familiar.

- Dios se lo llevó porque lo necesita más que nosotros". Esta respuesta propicia malestar, enojo, o molestia, "atribuyendo la responsabilidad de la muerte a Dios" ${ }^{43}$, y generando una falsa imagen del Cielo y de la persona fallecida, quien está ayudando a Dios, porque él solo no puede.

- " "Ya verás cómo al final ya se pondrá bien". Si se sabe que el desenlace es la muerte, esta respuesta generará incertidumbre y desconfianza ${ }^{44}$, o resentimiento hacia los familiares, por mentir, y hacia los sistemas de apoyo.

- Otras personas deciden caminar por la resignación ${ }^{45}$, y esperar "a ver qué sucede", dejando todo a una esperanza en que "Dios cambie su voluntad en el último minuto" y devuelva la vida y la salud.

\section{El duelo anticipado}

Algunas personas deciden caminar por el duelo anticipado y la aceptación del acompañamiento paliativo, que tiende a ser mucho más activo y guiado por la fuerza de la vida. El duelo anticipado está caracterizado por la aparición del proceso de duelo antes de la pérdida real del ser querido o de una situación particular. Se presenta especialmente en familiares y pacientes de enfermedades terminales o en la Unidad de Cuidados Intensivos, cuando la persona aún no ha muerto. Ante la lucha por mantenerse vivo o el acompañamiento a un familiar enfermo, si la enfermedad va ganando terreno, se pasa por momentos complejos como los señalados previamente, y se transita por la resignación hasta llegar a la aceptación. Los sentimientos de los pacientes y sus familiares -según Agustina Loitegui- se pueden caracterizar en los siguientes términos:

Junto con los síntomas de tristeza, ansiedad y enojo, característicos del duelo, el sujeto o la familia comenzarían a ensayar-mentalmente- las diferentes formas en las que la muerte se produciría, además de ir paralelamente adaptándose a ella y a sus pérdidas concomitantes. ${ }^{46}$

${ }^{43}$ Díaz, Mentiras piadosas: explicaciones que dificultan a los niños la comprensión de la muerte.

${ }^{44}$ Ibíd.

${ }^{45}$ La resignación es entendida como la actividad pasiva ante las circunstancias que no se pueden manejar, como la muerte. Es sentirse obligado a subordinarse pasivamente a la realidad de la muerte.

${ }^{46}$ Loitegui, Duelo anticipado: sobre el desarrollo del concepto y la importancia de su estudio y abordaje, 12. 
El duelo anticipado tiene intrínsecamente unas actividades que, desarrolladas adecuadamente y con acompañamiento, se encaminan hacia la aceptación del sufrimiento y de la muerte, en los casos de enfermos de difícil cura y al final de su vida. Algunas tareas que sugiere Agustina Loitegui son las siguientes ${ }^{47}$ :

- La familia debe mantenerse involucrada con el paciente, incluyéndolo en las actividades y eventos familiares lo máximo posible; al mismo tiempo, debe aprender a separarse del paciente, para diferenciarse de él e ir reconociendo que morirá en algún tiempo.

- Se debe empezar a asumir un cambio de roles: cada miembro debe acomodarse a las nuevas demandas al interior de la familia y asumir nuevas responsabilidades.

- $\quad$ Es necesario soportar los efectos del duelo, aprendiendo a controlar y reorientar los muchos sentimientos encontrados que afloran del duelo anticipado.

- También se debe empezar el camino de aceptar la realidad de la inevitabilidad de la muerte, de manera que los miembros de la familia asuman una serie de reacciones emocionales que los lleva al reconocimiento y aceptación creciente de la inevitabilidad de la muerte del enfermo.

Y es necesario despedirse, como dice Loitegui:

...esto puede ocurrir tanto a nivel verbal como no verbal y es el reconocimiento y aceptación de que la muerte está sucediendo. Es como si la familia tuviera que darle permiso al enfermo para morir, a pesar del dolor y la pena, deben manifestarle al enfermo que está bien que parta y despedirse. ${ }^{48}$

Es recomendable seguir los procesos del duelo anticipado acompañado de personas profesionales y debidamente capacitadas para hacerlo. Sin embargo, se corren riesgos de malinterpretar el seguimiento, los procesos y las intenciones de la familia y del paciente, lo cual puede generar daños psicológicos y resentimientos espirituales que después serán complicados de asumir terapéuticamente.

\section{Respuestas redentoras ante el sufrimiento y la muerte}

Existen personas que buscan un sentido productivo al sufrimiento y a la muerte. Esto es un asunto sorprendente porque la muerte se ve como una frustración, un fracaso, la terminación de planes y la destrucción de la vida; además, la visión se vuelve más crónica cuando va acompañada de sufrimientos paulatinos, prolongados, que requieren de medicinas y tratamientos costosos, económica y físicamente. Algunos investigadores

${ }^{47}$ Ibíd., 13.

${ }^{48}$ Ibíd. 
indican que es posible dar un valor sagrado al sufrimiento y a la muerte, pero que es necesario asumir otras perspectivas, como las que asume Jesús en la cruz, según narra Lc 23,43, con un horizonte redentor y productivo, como se señala a continuación.

\section{Escoger la actitud ante la muerte}

El camino de la actitud redentora del sufrimiento y la muerte se está encaminando por la aceptación ${ }^{49}$, pues ya que no se puede escoger la muerte, ni la manera de morir (normalmente), pero sí se puede escoger la actitud ante la muerte y, con una experiencia trascendente, la productividad del sufrimiento y la muerte.

Hablar del sentido de la muerte en una experiencia sin sentido conduce a preguntarse ¿̨cómo dar sentido a la muerte en experiencias sin sentido como el sufrimiento de pacientes terminales? Es como preguntarse por el sentido de los fenómenos que no quiere vivir el ser humano ${ }^{50}$. Como señala Spaemann: "Solo donde se acepta y se cree en un sentido universal, como sucede en la religión bíblica, llega a ser planteada

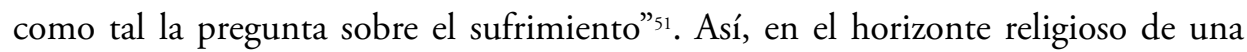
experiencia trascendente se le puede dar sentido al sufrimiento y a la muerte de los enfermos al final de la vida terrena.

El sufrimiento de Jesús tiene un sentido redentor (como se observa en Lc 23, 42-43), porque él ocupa el lugar de los condenados por el pecado ${ }^{52}$, de manera que al dar sentido al sufrimiento se enfrenta directamente el mal y se enriquece la existencia humana, haciendo que situaciones asimétricas como el sufrimiento o la muerte se conviertan en una fuente de vida para el paciente y sus acompañantes. Dicho de otra manera, quien padece sufrimientos los une al sacrificio redentor de Jesucristo, para que se vuelvan bendición hacia unas personas o instituciones escogidas para tal fin, lo cual genera solidaridad.

Entonces, se crea una alteridad de tal magnitud que el sufrimiento se convierte en motivo de realización para el paciente creyente y para su familia ${ }^{53}$, y esto conduce

\footnotetext{
${ }^{49}$ Es la decisión que se toma al reconocer los límites de la existencia humana; consiste en reconocer que después de la vida hay vida y que la muerte no es el fin sino el comienzo de la plenitud, así que la aceptación está cargada de una esperanza sostenida por la certeza de la trascendencia humana (Worden, $E l$ tratamiento del duelo: asesoramiento psicológico y terapia, 45; Barbero Gutiérrez, Sufrimiento y responsabilidad moral, 156).

${ }^{50}$ Spaemann, "El sentido del sufrimiento. Distintas actitudes ante el dolor humano", 1.

${ }^{51}$ Ibíd., 5.

${ }^{52} \mathrm{La}$ experiencia de la redención consiste en que un inocente ocupa el lugar del culpable. De esta manera, el sufrimiento puede tener un sentido redentor cuando el paciente y su familia unen su sufrimiento al sacrificio redentor de Jesucristo por un motivo determinado (Barbero Gutiérrez, Sufrimiento y responsabilidad moral, 156).
}

${ }^{53}$ Ibíd., 163. 
a una comprensión del sentido de la vida desde la entrega: porque el ser humano, en su fragilidad y debilidad, encuentra su fortaleza en la donación de su vida y en la búsqueda del mayor bienestar de sus familiares y amigos o de instituciones.

Así, a diferencia de las conclusiones de Barbero ${ }^{54}$, el sufrimiento y la muerte sí tienen sentido en la trascendencia, en la solidaridad y en la entrega, que es el pensamiento de Spaemann, según el cual es posible volver productivo el sinsentido del sufrimiento desde la experiencia con Dios:

Si el hombre no alcanza objetivamente su destino sin Dios, la exigencia subjetiva de un sentido absoluto, la necesidad de Dios, es una muestra de salud. Y la no necesidad de Dios, un defecto. Lo que ponga al hombre en la ocasión de descubrir subjetivamente la necesidad de Dios, es un medio para alcanzar la salvación..$^{55}$

Es posible brindar al paciente la alternativa del sentido redentor del sufrimiento y de la muerte; de igual manera está en él acoger esta propuesta o rechazarla porque, así como se ofrecen alternativas de curación efectiva o paliativa, se debe ofrecer la trascendente y reconciliadora con la vida, que conduzca a morir en paz y lograr la oportunidad de asumir el sufrimiento como una fortaleza, para redimir a amigos y a familiares.

\section{Aceptación y redención}

El "sufrimiento vicario" consiste en el "sufrimiento de quien en sí mismo no es culpable, sino que padece por otros" ${ }^{\prime 6}$, en medio de la experiencia cristiana, en la cual se ofrece el sufrimiento personal para que Dios lo devuelva como bendición en favor de otras personas. No se suprime el dolor somático, pero al dar sentido al sufrimiento -como anotan documentos del magisterio católico ${ }^{57}$ - este parece disminuir porque se genera paz y alegría (lejos de la alienación religiosa), que hacen que se relativice el sufrimiento y se comprenda que el miedo se da, no a lo desconocido, sino a perder lo conocido.

El paciente y sus familiares -especialmente quienes tienen la custodia del enfermo- se convierten en protagonistas y promotores de la vida, en actores del sentido de la muerte, porque se realizan los cuidados pertinentes con amor, paciencia y un acompańamiento como oblación, con alimentación adecuada, hidratación necesaria y

\footnotetext{
${ }^{54}$ Barbero Gutiérrez, Sufrimiento y responsabilidad moral.

${ }^{55}$ Spaemann, "El sentido del sufrimiento. Distintas actitudes ante el dolor humano", 7.

${ }^{56}$ Ibíd., 8.

${ }^{57}$ Juan Pablo II, Exhortación apostólica Salvifici doloris 5. Pontificio Consejo para la Pastoral de los Agentes Sanitarios, Carta de los agentes sanitarios, 68.
} 
atención oportuna al paciente ${ }^{58}$. La vida se asume con la dimensión de la resurrección y la misión que esta conlleva ${ }^{59}$.

Se contribuye a que el paciente ejerza sus derechos como agente regulador de la información que recibe y la manera de manejarla, el conocimiento o la omisión de la verdad sobre su situación física, el rango de recuperación o la perspectiva de esperanza, la elección de tratamientos, ya sean extremos o paliativos, el deseo de recibir atención y acompañamiento espiritual y la autonomía ante la situación que está viviendo ${ }^{60}$.

\section{Conclusiones generales}

Ante las situaciones límite de la existencia humana, algunos eligen luchar contra el sufrimiento atacando y aislándose egoístamente en su dolor; otros escogen buscar sentido al sufrimiento con elementos de autocrítica y con la esperanza de algo que sea mucho mejor a lo que se está viviendo en el momento; esto es sensible aunque incompleto y se puede equivocar en el camino; pero la mejor opción es dar sentido redentor al sufrimiento a partir de la solidaridad y la observancia de la esperanza desde el presente.

$\mathrm{Al}$ analizar distintas respuestas al sufrimiento y a la muerte, en especial en enfermos de difícil cura y al final de la vida física, es observable que se mueven en los extremos: por un lado se buscan respuestas médicas o espirituales extremas que pueden conducir a un mayor dolor y sufrimiento del paciente y de sus familiares, y conducir a una terrible frustración; por otro lado se recurre a la eutanasia para evitar mayores sufrimientos y acercar el desenlace, lo cual conduce a un descuido en la investigación y en el respeto a la dignidad humana.

Ambos extremos pueden tener amplias justificaciones, pero las consecuencias muestran la inconveniencia ética y el daño personal, médico y social, al mismo tiempo que deforman la imagen de Dios, como si él se complaciera con el sufrimiento humano ${ }^{61}$.

En la medida en que buscar sentido al sufrimiento puede generar más acompañamiento y comprensión, porque se recurre a la espiritualidad y se va mejorando la experiencia con la divinidad, crece la autocrítica y se fortalece la esperanza, pero se puede equivocar la búsqueda, porque los caminos de espiritualidad para mantener la esperanza son variados y es factible caer en la alienación. El punto intermedio que realiza más aportes éticos, médicos, familiares y sociales, como el acompañamiento

\footnotetext{
${ }^{58}$ Centeno Cortés y Vega Gutiérrez, "La muerte, el duelo y el equipo de salud", 9-10.

${ }^{59}$ Tenjo, "Regalos del Resucitado. Un comentario de Jn 20,19-23”, 278.

${ }^{60}$ Centeno Cortés y Vega Gutiérrez, "La muerte, el duelo y el equipo de salud", 11-13.

${ }^{61}$ Varone, El Dios sádico. ¿Ama Dios el sufrimiento?, 265.
} 
espiritual que busca desde la dimensión trascendente, es dar un sentido redentor al sufrimiento y a la muerte, asumiendo el valor redentor y la productividad existencial del "sufrimiento vicario".

Para realizar el acompañamiento a personas que conviven con enfermedades de difícil cura se opta por el sentido redentor del sufrimiento, ya que la ayuda necesaria a nivel médico e investigativo se sigue realizando, aun cuando es muy costosa económicamente. Se propone una espiritualidad bíblica, particularmente desde el sufrimiento y la muerte de Jesús, para proyectar su vida más allá de la muerte, generando una experiencia soteriológica, porque en la cruz se soluciona el problema del sufrimiento querido por Dios.

La persona, en su situación de enfermo terminal, tiene derecho a recibir "atención religiosa en consonancia con sus propias creencias y deseos"62. De esta manera, para evitar extremos espiritualistas y alienantes con promesas de sanaciones extrañas, se debe proponer una espiritualidad que trabaje y desarrolle la dignidad de la persona, la productividad del sufrimiento y el fin metahistórico de la muerte.

El sufrimiento y la muerte, como experiencias de pérdida y fracaso, se pueden transformar en un fenómeno productor de solidaridad y salvación, cuando se le da un sentido redentor desde la dimensión espiritual del ser humano. Sin duda alguna, debe existir una experiencia personal con Jesucristo para asumir este estilo de vida, nada alienante y totalmente productivo en la dignificación del ser humano.

La esperanza en la vida después de la vida genera un estilo existencial optimista, que contagia de alegría, incluso en situaciones avanzadas de enfermedades terminales, porque se experimenta el duelo anticipado; pero, con la correcta orientación, se camina por senderos de aceptación, con una fuerza de vida que se contagia.

Es necesario conocer la fuerza salvadora de vidas y atender con esmero a las personas que conviven con enfermedades de difícil cura, para contribuir al crecimiento personal que enseñe a vivir nuevas experiencias que van más allá de la vida terrena. Dicho dinamismo conduce a seguir desarrollando las formas de afrontar las enfermedades al final de la existencia terrena, a vivir cierta familiaridad con la muerte, para ordenar la vida en función de la trascendencia en categorías de "paraíso", y a asumir la muerte con esperanza de una vida después de la vida.

La vida es tan dinámica y tan creativa que no se detiene con la muerte, sino que trasciende hacia la plenitud, hacia la trascendencia, hacia la intimidad con el Creador mismo. La experiencia de la muerte conduce a que la creatura se encuentre con el Creador en una intimidad más allá del tiempo.

\footnotetext{
${ }^{62}$ Centeno Cortés y Vega Gutiérrez, "La muerte, el duelo y el equipo de salud", 13
} 


\section{Referencias}

Barbero Gutiérrez, Javier. Sufrimiento y responsabilidad moral. Madrid: Instituto Madrileño de la Salud, 2003.

Brown, Raymond. E. La muerte del Mesías. Tomo II. Navarra: Verbo Divino, 2006.

Centeno Cortés, Carlos y Javier Vega Gutiérrez. "La muerte, el duelo y el equipo de salud": Revista de salud pública 2, Vol. 2 (2008): 14-23.

Díaz, Patricia. "Mentiras piadosas: explicaciones que dificultan a los nińos la comprensión de la muerte". Blog Fundación Mario Losantos del Campo, http://blog. fundacionmlc.org/mentiras-piadosas (consultada el 7 de agosto de 2014).

Fitzmyer, Joseph A. El Evangelio según Lucas. Tomo IV. Madrid: Cristiandad, 1988.

García Marcos, Fermín. "Aspectos éticos del transplante de órganos”. Cuadernos de bioética 45, 2 (2001): 253-265.

Herranz, Gonzalo. Comentarios al Código de Ética y Deontología Médica de la Organización Médica Colegial. Pamplona: Eunsa, 1992.

. "Eutanasia o medicina": Cuadernos de bioética 4, 4 (1990): 21-23.

Juan Pablo II. Exhortación apostólica Salvifici doloris. Roma: Editrice Vaticana, 1984.

León Correa, Francisco Javier. "Bioética de la atención de enfermería al enfermo terminal”. NOVA (2003): 1-116. Disponible en: http://unicolmayor.edu.co/ publicaciones/index.php/nova/article/view/5/

. "El debate actual sobre la legislación de la eutanasia": Revista Ars médica 12 (2006): 39-52.

Loitegui, Agustina. Duelo anticipado: sobre el desarrollo del concepto y la importancia de su estudio y abordaje. Buenos Aires: Universidad de Belgrano, 2008.

Marshall, I. Howard. The Gospel of Luke: A Commentary on the Greek Text. Grand Rapids (MI): Eerdmans Publishing Company, 1978.

Morales, David. "La medicina contemporánea y su vínculo con el espiritismo. Notas de la Sociedad Espiritista Cubana” Sociedad Espiritista Cubana, http://www. sociedadespiritistacubana.org/La_medicina_contemporanea.htm (consultado el 20 de julio de 2016).

Ortiz, Pedro. Concordancia manual y diccionario griego-español del Nuevo Testamento. Madrid: Sociedad Bíblica: 1997. 
Ospina, Ana María. El paciente terminal, la familia, el proceso de duelo y la acción profesional. Cali: Facultad de Humanidades de la Universidad del Valle, 2005.

Pontificio Consejo para la Pastoral de los Agentes Sanitarios. Carta de los agentes sanitarios. Madrid: Palabra, 1995.

Porta, José y Carlos Guinovart. Definición y opiniones acerca de la sedación terminal: estudio multicéntrico catalano. Madrid: Medicina Paliativa, 1999.

Rivera, Jordi. “¿Qué significa estar en estado vegetativo?” Siervas de los corazones traspasados de Jesús y María, http://www.corazones.org/moral/enfermedad/ estado_vegetativo.htm (consultado el 20 julio de 2014).

Rengstof, Kart Heinrich. Nuovo Testamento. Il Vangelo secondo Luca. Brescia: Paideia Editrice, 1980.

Spaemann, Robert. "El sentido del sufrimiento. Distintas actitudes ante el dolor humano". Revista Atlántida 15, Vol I (2005): 7-23.

Sureda González, Manuel. "Aproximación al enfermo terminal y a la muerte". Associació Catalana d'Estudis Bioètics, ACEB, http://bioetica.cat/wp-content/ uploads/2013/01/APROXIMACION-AL-ENFERMO-TERMINAL-Y-ALA-MUERTE.pdf (consultado el 30 de mayo de 2018).

Tenjo Cogollo, Manuel. "La perseverancia en el seguimiento de Jesucristo a partir de algunas comunidades en el Minuto de Dios y confrontación con Lc 8,11-15". Pontificia Universidad Javeriana, http://www.javeriana.edu.co/biblos/tesis/ teologia/tesis46.pdf (consultado el 5 julio 2013).

. "Regalos del Resucitado. Un comentario de Jn 20, 19-23". Revista Franciscanum 164, Vol. LVII (2015): 255-280.

Varone, Francois. El Dios sádico. ¿Ama Dios el sufrimiento? Santander: Sal Terrae, 1988.

Worden, W. El tratamiento del duelo: asesoramiento psicológico y terapia. Barcelona: Paidós, 2004. 